\title{
Footprint: ignoring the facts that don't fit the theory
}

\section{The eco-sceptic idea that wealth leads to sustainability overlooks all reasonable evidence.}

Sir - Your News report "Ecological

footprint forecasts face sceptical challenge"

(Nature 419, 656; 2002), stating that Bjorn

Lomborg's environmental-policy group

disputes the usefulness of the 'ecological

footprint' concept, comes as no surprise

to those familiar with Lomborg's recent

work. He argued in The Skeptical Environmentalist: Measuring the Real State of the World (Cambridge University Press, New York, 2001) that societies become "greener" and presumably more sustainable as they accumulate wealth and purchasing power. To support this 'wealth hypothesis' he correlates his preferred measure of environmental impact with gross domestic product (GDP) by country. However, his preferred measure is the Environmental Sustainability Index (ESI) generated by the World Economic Forum (WEF).

This index, plagued with methodological problems, offers no useful information about our long-term affairs and prospects. It considers 67 variables divided among 22 environmental indicators, most of which have little to do with a region's ability to provide ecosystem goods and services.
For example, high petrol prices and the memberships of environmental organizations are tabulated, as are the number of scientific articles a country publishes and its record of regulatory innovation - but these probably do not relate to the general workings of the biosphere.

Additionally, none of the variables is weighted appropriately, so ecologically tenable variables such as soil degradation, water availability, ecological deficit and fertility rate are considered equal to petrol prices and measures of political corruption. To its credit, the WEF report recognizes these limitations, some of which may be addressed in future versions of the index.

The ecological-footprint concept offers a snapshot of our resource demand independent of GDP — unlike the ESI. Thus, by recognizing the reality of biophysical limits, a country's ecological footprint offers a conservative measure of the total productive land, water and resources required to support a given population and cope with its waste materials. Such measures are necessary before we can hope to deal with more difficult concepts such as regional and global sustainability. Lomborg's group misses the point by stating "there is no 'correct' ecological footprint". No one has claimed that an ecological footprint calculation is "correct" and should be accepted uncritically.

Estimating anything will always be subject to error - a fact that a statistician such as Lomborg surely recognizes. But given the urgent need to understand fully our global predicament and true prospects for sustainability, should we abandon conceptual tools if they rely on estimates?

I am aware of no measure of ecological footprint that supports Lomborg's wealth hypothesis, which may explain why he dismisses the value of the ecologicalfootprint concept. It is not clear to me how Lomborg's view will contribute to sustaining a growing human population over the long term, given the challenges of becoming regionally sustainable.

Keith M. Vogelsang

Department of Biology, Jordan Hall 142,

Indiana University, Bloomington,

Indiana 47405-3700, USA

\section{Footprint: our impact on Earth is getting heavier}

Sir - Bjorn Lomborg's comments as reported in your recent News story (Nature 419,656 ; 2002) betray ignorance of ecological-footprint analysis (EFA). This is a method I proposed (W. E. Rees Popul. Environ. 24, 15-46; 2002) specifically to assess the assertions made by some economists that, because of technological advances, the human economy is "dematerializing" or "decoupling" from the natural world. If true, this implies that modern society is becoming less dependent on nature, and can be used to justify further economic growth. If false, the additional stress likely to be imposed on the natural world will be disastrous.

Certainly, no single index can represent the total human impact on the ecosphere. However, EFA is comprehensive enough to show, unambiguously, that the human eco-footprint on Earth is steadily increasing. Comparative studies (such as the Worldwide Fund for Nature's Living Planet Report 2002, criticized by Lomborg) show that the most technologically advanced nations are the most energyand material-intensive and have the largest per-capita ecological footprints. Hence, the consumer lifestyles of their average citizens (and of the wealthy residents of the developing world) are the least ecologically sustainable on Earth, and cannot be safely extended to humans everywhere.

Lomborg's ignorance of eco-footprint science is illustrated by his claim that it ignores the potential growth in the use of renewable resources, and that if the use of such resources increases, the 2050 footprint would not be as large as projected. The fact is that EFA is already largely based on use of renewable resources, with the exception of the fossil-fuel (carbon sink) component. A shift to exclusive use of renewable energy does not necessarily imply a reduction in the eco-footprint.

Biomass fuels, for example, are likely on thermodynamic grounds alone to demand a larger growing area than the amount of land needed to provide the energetically equivalent amount of fossil energy (via carbon assimilation) today. One proposed 'renewable' resource, fuel ethanol production, is not even a net source of energy. In the United States, 70\% more energy (mostly fossil fuel) is consumed in producing a litre of ethanol than is contained in the product. Even without counting the energy cost of the fermentation and distillation process, or the carbon-sink footprint of the fossil fuel used to grow the maize feedstock, the average US automobile would require 4.4 hectares of cropland to provide its annual fuel requirements. (This whopping — but only partial — fuel eco-footprint is about seven times the cropland needed annually to feed one person in the United States.) To run all US cars on ethanol would require an area of cropland equivalent to nearly the total US land area. More generally, the United States uses 85\% more fossil energy each year than the total energy captured by all its plant biomass over the same period. Clearly, regardless of the efficiency of the conversion technology, there is no possibility of renewable biomass substituting, joule for joule, for fossil fuel.

The much-touted solar alternatives may not fare much better. Although the solar flux represents a vast flow of potential energy, various analysts argue, from both thermodynamic principles and empirical data, that humanity faces enormous technological obstacles in converting this flow into the energetic equivalent of contemporary fossil-fuel use.

In the light of such data and the implicit uncertainty about prospects for sustainability, Lomborg's "sceptical challenge" to the ecological footprint concept falls flat. EFA may be static, but this does not invalidate estimates of future footprints based on reasonable 
assumptions about technological development. Dynamic modelling is just as vulnerable to implicit error in this regard. William E. Rees

School of Community and Regional Planning,

University of British Columbia,

6333 Memorial Road, Vancouver,

British Columbia V6T 1Z2, Canada

\section{Xenotransplantation's benefits outweigh risks}

Sir - Your News item "Diabetes trial stirs debate on safety of xenotransplants" (Nature 419,$5 ; 2002$ ), discussing our clinical trial of pancreatic islet xenotransplantation, states: "Mexico has no published guidelines on clinical trials in xenotransplantation."

This is untrue. Mexico has a general health law that regulates the conduct of all experimental investigation in human beings; it also regulates organ and tissue transplantation, and xenotransplantation, which was added recently. The protocol for our clinical trial was approved by the research, ethics and biosafety committees of our institution and of the National Autonomous University of Mexico Medical School.

Your article did not mention the existence of other published studies on porcine-human islet xenotransplantation, although these studies are admittedly small, use different methods from ours and do not show significant benefit to patients. With regard to your reporter's comment about the need to test "any proposed approach" on non-human primates, there are many examples in the fields of both transplantation and diabetes where experimental studies in humans are performed following evidence of benefit derived only from other mammalian models. Indeed, one of the problems we faced was that there is no appropriate model for auto-immune diabetes in non-human primates.

You report our critics' views that we should have undertaken preclinical studies before proceeding, but vast amounts of preclinical data on animal models already exist, both on efficacy of islet xenotransplantation and the protective effects of Sertoli cells, including our own published work. We have not published some of our work, to protect patents. But we consider the available literature sufficient to justify our trials on young diabetic patients, the population that stands to benefit most.

You report our critics as stating that our work was on patients too young to give proper informed consent. We recruited adolescent and high-school students because they had had diabetes type 1 for more than four years, so that spontaneous remission would not occur, yet there were no diabetic complications typical of adult patients. It is our strong contention that they were old enough to understand fully the potential risks and responsibilities. We had several meetings with the patients and their parents to explain in detail the procedure. After time for reflection, they signed extensive informed consent forms conforming to international requirements, for example the Helsinki declaration.

Type 1 diabetes causes the death of more than $40 \%$ of patients before they reach the age of 40 , and is a leading cause of terminal renal insufficiency and blindness, among other devastating complications. We believe that the benefits of better metabolic control, and insulin and immunosuppression independence, offered by pancreatic islet xenotransplantation far outweigh the risks.

Rafael Valdes Gonzalez

Hospital Infantil de México "Federico Gomez", Laboratorio de Xenotrasplantes, Edificio Mundet $4^{\circ}$ Piso, Calle Dr Marquez 162, Col. Doctores, CP 06720, México D.F.

\section{UK government closes its eyes to medical needs}

Sir - Readers of Nature may get the impression that funding for basic research in the United Kingdom is in good health ("Calling for entrepreneurs: London" Naturejobs 19 September, 4-5; 2002). We wish to put the record straight.

The UK government uses the periodic Research Assessment Exercise (RAE) to determine levels of funding for university departments and institutes. Following the latest RAE, funding for hospital-based clinical subjects, which underpins the core of translational research in medical schools across the United Kingdom, was severely cut. Despite having received, for the third consecutive time, the highest possible rating $\left(5^{*}\right)$, the Institute of Ophthalmology in London faces a $19.7 \%$ cut in its predicted annual budget because the government has failed to honour its pre-RAE fiscal commitments. The problem is even greater for those who received a rating of 5 and who now face a massive $38 \%$ cut.

This takes $\mathfrak{£} 970,000$ (US\$1.5 million) a year out of our operating budget. We are unable to appoint even a single technical post that we require to run newly commissioned laboratories, which puts extra stress on academic staff. The cuts also exacerbate the financial difficulties faced by our parent body, University College London, after years of underfunding.

The reason UK medical schools are having problems is self-evident, and the crisis extends across the country. In the longer term our institute, together with others in hospital-based clinical subjects, will be less able to fulfil its mission, which is to deliver the translational research that enables laboratory science to be developed into clinical trials and ultimately into benefits to patients.

The message appears to be that, with regard to translational medical research, the government is not only blind to the achievements of $5^{\star}$ departments and institutes, it has also, incomprehensibly, decided to slash the support they receive. We also suspect that the cuts are due at least in part to inept planning and muddled thinking. Institutes such as ours have to budget, recruit and develop a coherent research strategy within the constraints of government policy. It is therefore essential that the government keeps its promises. This it has not done. In the United Kingdom the phrase 'science policy' has become an oxymoron.

If, as I. B. Holland suggests (Nature 419, 248 ; 2002), underfunding is less acute here than in other European countries, then the prospects for our continent of beleaguered researchers must be bleak. Governments are often short-sighted when it comes to policy development, but in this case we are confronted by a total lack of vision. And as we are only too well aware at this institute, myopia may be corrected but blindness remains virtually untreatable.

Stephen E. Moss, Gary Rubin, John Greenwood, Adam Sillito Institute of Ophthalmology, University College London, 11-43 Bath Street, London EC1V 9EL, UK

\section{Mother knows best}

Sir - In his otherwise excellent News and Views "The grand assault" (Nature 419, 493-494; 2002), Russell F. Doolittle writes: "Eukaryotes can be loosely defined as organisms whose cells have nuclei and cytoskeletons, distinguishing them from the Bacteria and the Archaea, neither of which has introns in their coding sequences."

Bacteria and the phage that infect them do contain introns in their genomes. The first example of an intron in a bacterial system was found in the thymidylate synthase gene of bacteriophage T4 (F. K. Chu, G. F. Maley, F. Maley and M. Belfort Proc. Natl Acad. Sci. USA 81, 3049-3053; 1984) — the last author being my mother. Since then, hundreds of introns have been found in archaea, bacteria and their phage.

It has been a long time since I uttered these words, but I couldn't be more proud to say: "Mommy told me so."

\section{Gabriel M. Belfort}

Department of Biochemistry, K-building,

Boston University School of Medicine, 715 Albany

Street, Boston, Massachusetts 02118, USA 